\title{
Educoração: histórias, experiências e partilhas de aprendizagem e afetividade na escola
}

http://dx.doi.org/10.11606/1807-5509201800020233

\author{
Janir Coutinho BATISTA* \\ Paulo Cezar NUNES JUNIOR ${ }^{* *}$ \\ Elaine PRODÓCIMO*
}

*Faculdade de Educação Física, Universidade Estadual de Campinas, Campinas, SP, Brasil. **Universidade Federal de Itajubá, Itajubá, MG, Brasil.

\section{Resumo}

0 presente estudo tem por objetivo analisar a proposta do Educoração, projeto criado para atuar no desenvolvimento afetivo da criança que se utiliza de diversas ferramentas (canções, rodas de conversa, jogos cooperativos, posturas de yoga e contação de histórias) a ser realizado no contexto escolar. A implementação da proposta ocorreu em uma escola pública do município de Cerquilho (SP), em 8 encontros de uma hora e meia de duração, com frequência semanal e participaram 23 crianças do primeiro ano do ensino fundamental. Trata-se de uma pesquisa participante e como procedimentos metodológicos foram feitas observações com registro de campo, entrevistas com professora da turma e diretora da escola e questionários. Os dados obtidos foram interpretados por meio da análise de conteúdo e organizados em três grandes categorias de análise: empatia, autoestima e aprendizagem. Os resultados mostraram que, somadas à participação do professor, as dinâmicas da proposta influenciaram na afetividade infantil e promoveram uma melhora no cotidiano da sala de aula. As atividades do Educoração contribuiram de maneira direta para que fossem abordados diversos aspectos relativos à afetividade e ao convivio das crianças na escola. Além da mudança nas relações entre as crianças e a professora e, da maior atenção de uns com os outros, a professora relatou que depois das intervenções conseguiu realizar seu trabalho com maior engajamento e interesse dos alunos, fato que permitiu que o projeto se ramificasse para outras turmas na escola.

Palavras-Chave: Afetividade; Educação; Aprendizagem; Ensino Fundamental.

\section{Introdução}

Nossa educação básica apresenta lacunas que são fontes de inúmeras críticas acerca do modelo de ensino, principalmente no âmbito emocional e afetivo ${ }^{1-2}$. As pilastras que sustentam esta problemática estão estabelecidas não só pelas arcaicas estruturas pedagógicas que buscam a disciplina dos corpos, mas também pelas técnicas de avaliação e classificação que geralmente privam o desenvolvimento afetivo dos alunos ${ }^{3}$. A ausência de uma pedagogia que potencialize o aspecto afetivo é um dos fatores que torna o ambiente escolar muitas vezes sem atrativos e desinteressante, podendo provocar nos alunos atitudes consideradas inadequadas socialmente, e, como consequência, os mesmos passam a ser adjetivados de baderneiros, bagunceiros, indisciplinados e muitas vezes categorizados como hiperativos ou com problemas de déficit de atenção.
Segundo GARCIA ${ }^{4}$ a indisciplina pode ser considerada uma forma de resistência à situação de não acolhimento do aluno por parte da escola. Não é por acaso que diferentes formas de indisciplina e mesmo violência, entre elas o bullying, são hoje temas muito discutidos na área da educação e estão diretamente ligados à afetividade no cotidiano escolar ${ }^{5}$.

Diante das exigências de cumprimento de conteúdos, o estímulo ao desenvolvimento das capacidades afetivas torna-se marginal à prática pedagógica e sem espaço na rotina escolar, embotando sentimentos e emoções, e privando os alunos de um ensino mais amplo e humanizado. Ao agir nesta direção, nosso sistema educacional (políticas públicas, instituiçóes de ensino e seus agentes - diretores, gestores, professores etc.) se esquece de que as crianças 
precisam de um ambiente onde possam satisfazer suas necessidades emocionais de forma a desenvolver uma sensibilidade requerida para a construção de vínculos sociais e afetivos ${ }^{6}$.

Consoante a WALLON ${ }^{7}$ a dimensão afetiva é um aspecto que deve ser trabalhado no desenvolvimento infantil uma vez que está relacionada diretamente com a formação humana. Para o autor, citado por Almeida $^{2}$ a afetividade "é o termo utilizado para identificar um domínio funcional abrangente e, nesse domínio funcional, aparecem diferentes manifestaçôes: desde as primeiras basicamente orgânicas, até as diferenciadas como as emoções, os sentimentos e as paixóes" (p. 346-347).

De acordo com Leite e Tagliaferro ${ }^{8}$, a afetividade, engloba tanto sentimentos (de origem psicológica) quanto emoçóes (de origem biológica). Para Wallon ${ }^{9}$ (p. 122):

É inevitável que as influências afetivas que rodeiam a criança desde o berço tenham sobre sua evolução mental uma ação determinante. (...) porque se dirigem, à medida que ela desperta, a automatismos que no desenvolvimento espontâneo das estruturas nervosas contém em potência (...). Assim, o social se amálgama ao orgânico.

As emoções, para o autor, apresentam função altamente relevante no desenvolvimento psíquico além de estarem intimamente relacionadas à própria sobrevivência, pois são capazes de mobilizar o ambiente para as necessidades do bebê ${ }^{10}$.

Ferreira e Acioly-Régnier ${ }^{11}$, pautados em Wallon, falam da afetividade orgânica, ligada às emoçóes; e da afetividade em que o fator social está incorporado.

A noção de pessoa apresentada por Wallon aponta para uma síntese dos conjuntos funcionais (afetivo, motor e cognitivo) e para a integraçáo dinâmica entre o orgânico e o social. Sua posição teórica era contrária à compreensão do humano de forma fragmentada ${ }^{11}$ (p. 28).

Outro aspecto discutido na teoria do autor é a relação entre afetividade e inteligência, que, no início da vida “(...) estão sincreticamente misturadas, com o predomínio da primeira"10 (p. 90), e que, apesar da diferenciação que segue-se, “(...) as aquisiçóes de cada uma repercutem sobre a outra permanentemente" (p. 90).

Sobre as fases do desenvolvimento da afetividade, propóe que a fase inicial se caracteriza pelas emoçôes, é a chamada afetividade somática; com a construção da função simbólica e a incorporação da linguagem (oral e escrita) a afetividade se constitui em sua forma cognitiva; e finalmente na puberdade torna-se novamente altamente relevante com a incorporação da função categorial ${ }^{10}$. Desta forma, cabe à educação em cada um desses momentos: "A satisfação das necessidades orgânicas e afetivas, a oportunidade para a manipulação da realidade e a estimulação da função simbólica, depois a construção de si mesmo" ${ }^{10}$ (p. 95).

Neste sentido, é preciso considerar uma ideia discutida por MAHONEY e Almeida ${ }^{12}$, que afirmam que olhar para a educação exige o estudo do meio ou dos meios em que ela se desenvolve, pois, a mesma situa-se dentro de uma zona de interação entre os sujeitos que a constituem.

Segundo Cavallet ${ }^{13}$, ao olhar de forma mais abrangente para o contexto social vemos que as instituiçôes de ensino transitam entre o modelo ético e moral da educação e o modelo de formação técnica para o mercado. Trata-se, portanto, de uma complexa rede que implica no modo como a escola deve se portar frente às exigências do mercado, $\mathrm{e}$ que na maioria das vezes educa para a informação e não visando o pleno desenvolvimento do sujeito, evidenciando uma aprendizagem técnica que normatiza a disciplina requerida pelo modelo de mundo, em detrimento do aspecto subjetivo e desenvolvimento de uma consciência afetiva.

Toda esta conjuntura gera reflexos no âmbito escolar, os quais podem ser observados na relação muitas vezes distante entre aluno e professor e na desmotivação para a aprendizagem ${ }^{12}$. A falta de laços afetivos que dáo suporte ao desenvolvimento do aluno fragiliza a estrutura escolar. Segundo Assman e Sung ${ }^{6}$,

Educar é, fundamentalmente, criar condiçóes para acessos a experiências de aprendizagem. O fruto da educação não pode resumir-se a alguns saberes formalizados [...] Portanto, não basta a disponibilidade funcional e burocrática da educação (o mero acesso a escola). (p. 286).

Não basta ter uma aprendizagem oferecida como lição formalizada, é preciso também fomentar um envolvimento pessoal que transmita a paixão pelo aprender e pelo buscar seu sentido no que é ensinado. Logo, a educação não deve ser pensada apenas por suas diversas obrigaçóes curriculares, mas deve olhar para as pessoas envolvidas no 
processo. Tal ideia é endossada pelos estudos de GALVÃO ${ }^{14}$ que salienta "a importância da atmosfera escolar e do clima favorável de interaçóes para o aprendizado do aluno, a qual influencia a conduta do individuo e sua aprendizagem" (p. 85).

A afetividade é, portanto, uma facilitadora da aprendizagem e do desenvolvimento infantil, além de ser, ela mesma, fator essencial para uma formação mais humana ${ }^{1-2}$. Logo, neste artigo, faremos uso do conceito de afetividade pelo viés educativo, a partir da relação que se estabelece entre professor-alunos, alunos-alunos e aluno e ele mesmo, impulsionada pela expressão dos sentimentos e das emoçóes que se atualizam nesta relação. Segundo Mahoney e Almeida ${ }^{12}$ o principal sentido do termo afetividade "refere-se à capacidade, à disposição do ser humano de ser afetado pelo mundo externo/interno por sensaçóes ligadas a tonalidades agradáveis ou desagradáveis" (p. 5). É pensando neste sentido de "afetar-se" que salientamos a importância de iniciativas pedagógicas que de fato façam da afetividade uma prática cotidiana no contexto escolar.

Para isto, faz-se necessário que o professor se desprenda das velhas concepçóes e busque novos horizontes que contribuam não só para o conhecimento, mas principalmente para as relaçóes humanas. A postura desse profissional se manifesta na percepção e na sensibilidade aos interesses das crianças que, em cada idade, diferem em seu pensamento e modo de sentir o mundo. Como aponta Alves ${ }^{15}$, educar tem relação direta com sedução. Assim sendo, o professor deve procurar uma forma de ensinar que esteja em sintonia com o prazer de apreender, uma vez que a aprendizagem deve ser um constante encantamento. Para isto é necessário olhar as crianças e buscar a formação de laços afetivos, já que a escola é, na maioria das vezes, o primeiro agente socializador fora do círculo familiar da criança ${ }^{12}$.

Logo, os professores devem ser capacitados a terem alternativas pedagógicas que trabalhem com a afetividade e que fortaleçam a relação entre aqueles que partilham o cotidiano escolar. Neste sentido, o projeto Educoraçáo surge como uma proposta pedagógica que viabiliza o relacionamento interpessoal e intrapessoal, auxiliando na relaçáo ensino-aprendizado e contribuindo para um sistema educacional mais adequado à formação afetiva infantil.

\section{A proposta: apresentando uma nova história}

O Educoração é um projeto destinado às crianças do ensino infantil e primeiras séries do ensino fundamental, desenvolvido pela antropóloga e psicóloga Susan Andrews em conjunto com educadoras ligadas a ONG Instituto Visão Futuro ${ }^{a}$. O projeto há quinze anos vem sendo trabalhado na educação infantil no Centro Educativo Espaço $\mathrm{CreSer}^{\mathrm{b}}$, localizado na referida ONG, e teve origem na necessidade de criar uma alternativa pedagógica pautada no desenvolvimento integral da criança, utilizando-se a afetividade como mediadora no processo educativo $^{16}$.

Levando-se em conta que as crianças participantes da proposta encontram-se na fase da afetividade simbólica ${ }^{10}$, como recurso pedagógico o projeto utiliza-se de cançôes, exercícios corporais e jogos cooperativos com a intenção de desenvolver competências como respeito e empatia. Por meio de dinâmicas de grupo, as crianças são convidadas a sentirem-se em conexão com os amigos, família e com aqueles com os quais elas convivem trabalhando, assim, com a socialização e potencializando a afetividade. Além disso, por meio de uma técnica de meditação, as crianças são estimuladas a concentrarse e convidadas à introspecçáo como forma de tomar mais contato consigo.

O Educoração apoia-se em dois pilares fundamentais: o Círculo do Amor e o Círculo Mágico. O primeiro engloba uma série de cançóes, posturas de yoga, técnicas de meditação e relaxamento que incentivam as crianças à importância de sentir a conexão consigo mesmas e com o meio. O segundo é composto por um momento de contaçấo de histórias ao redor de um pedaço de tecido, onde bonecos e cenários "ganham vida" e ensinam a importância dos laços afetivos na relação humana. Ao final desta dinâmica é realizada uma roda de conversa e é desenvolvido o exercício da escuta empática, momento em que as crianças expressam como estão se sentindo e aquilo que apreenderam durante o dia.

As diversas técnicas mencionadas podem ser praticadas diariamente em momentos da rotina escolar, e tem também por objetivo amenizar o estigma da escola como lugar hostil e mostrar que as crianças podem ser acolhidas neste ambiente, assim, fortalecendo os laços entre os envolvidos. 


\section{Método}

A pesquisa foi desenvolvida numa escola municipal, na cidade de Cerquilho, interior de Sáo Paulo, a qual será mantida em anonimato por preceitos éticos. Participaram deste projeto 23 crianças, com idade entre 7 e 8 anos, cursando o segundo ano do ensino fundamental.

As intervençôes aconteceram às terças-feiras no período matutino durante 8 semanas. Cada um dos encontros tinha a carga horária de uma hora e meia e as atividades eram guiadas por dois facilitadores, sendo que um deles atuou como pesquisador deste estudo. Trata-se de uma pesquisa de caráter qualitativo do tipo exploratório.

Para tanto, utilizou-se a observação participante como forma de estabelecer um contato mais próximo com o campo de pesquisa. Segundo MinaYo ${ }^{17}$ este tipo de procedimento possibilita um contato mais informal do pesquisador com o campo e coloca-o em interaçáo com os sujeitos, possibilitando que o pesquisador participe da vida deles, modificando e sendo modificado pelo processo.

Como instrumento de investigação utilizou-se de observação com registro em diário de campo; relatórios produzidos pelos facilitadores e pela professora; questionários com as crianças; e entrevistas semiestruturadas com a diretora e professora. $\mathrm{O}$ conteúdo dos relatórios dos facilitadores faz referência às impressōes das atividades e as reverberaçóes destes encontros no cotidiano da sala de aula. Os relatórios realizados pela professora incluíram também fatos ocorridos durante a semana e que tinham relação com os aspectos trabalhados no projeto, principalmente aqueles ligados às relaçóes interpessoais.

As informaçóes obtidas da diretora e professora por meio das entrevistas semiestruturadas, realizadas

\section{Resultados}

De acordo com os dados obtidos, a implementação do projeto Educoração gerou uma série de resultados surpreendentes e histórias transformadoras que certamente auxiliaram no desenvolvimento afetivo das crianças na escola municipal de Cerquilho.

No início, a chegada de novas estratégias de ensino-aprendizagem na escola gerou uma série de incertezas, isso porque os próprios educadores e a estrutura de ensino da escola apresentaram antes e ao final do projeto, tinham por objetivo adentrar o campo de investigação desta pesquisa, a saber, a descrição da relação aluno-aluno, aluno-professor, aluno-escola e sua relaçáo com a aprendizagem. O material foi coletado na própria escola e as entrevistas foram devidamente gravadas e transcritas para posterior análise.

De modo a preservar a identidade das pessoas envolvidas na pesquisa, os trechos do material levantado, que compóem a narrativa, foram referenciados como: relatório facilitador/ pesquisador, quando se trata de observaçáo realizada pelo próprio pesquisador; relatório facilitador, quando refere-se a observação da outra pessoa que desenvolveu a proposta juntamente com o pesquisador; relatório professora, quando a observação foi feita pela professora; entrevista diretora e entrevista professora; e os questionários respondidos pelas crianças foram numerados.

Por envolver a participação de seres humanos, tomaram-se os devidos cuidados éticos, assim, todos os sujeitos envolvidos na pesquisa assinaram um Termo de Consentimento Livre e Esclarecido que continha as informaçóes sobre a proposta do estudo. No caso das crianças, este termo foi assinado pelos pais ou familiares maiores de idade.

Os dados obtidos nos questionários, entrevistas e observações foram interpretados por meio da análise de conteúdo. Segundo Bardin ${ }^{18}$, trata-se de um conjunto de técnicas de análise das narrativas e pode ser aplicado a um vasto campo de pesquisa. Possibilita que uma leitura mais profunda seja realizada a partir dos dados que foram coletados. Assim, agrupamos os dados e elegemos categorias temáticas a partir dos assuntos mais reincidentes.

uma resistência diante desta nova maneira de intervir que atua em uma direção diferente dos métodos convencionais. Observa-se este primeiro momento de apreensão na entrevista inicial feita com a professora: "Tenho receio que o projeto possa atrapalhar a dinâmica de aula, mas como é algo que vem nos ensinar vale a pena tentar."

Se num primeiro momento foi preciso vencer estes receios, logo depois as dinâmicas do projeto mostraram-se como um potente recurso para a 
integração e participação dos alunos na sala de aula. Segundo os registros de campo foi possível captar estas mudanças e para facilitar a apresentação destes dados, três grandes categorias de análise foram elaboradas como forma de agrupar e organizar as informaçóes obtidas nesta pesquisa, a saber: a) Empatia (capacidade de escuta e relacionamento aluno-aluno e professor-aluno); b) Autoestima (relação do aluno consigo mesmo) e c) Aprendizagem (envolvendo aspectos como atenção, concentração e participação em sala).

\section{Empatia}

Nessa categoria foram englobados os dados que correspondem ao colocar-se no lugar do outro e reconhecer o outro como um sujeito de direitos. Segundo Hess e Weigand ${ }^{19}$ "as dificuldades de aprendizagem dos alunos se constroem na sala de aula, na interação pedagógica e são o resultado de não ajustamento entre eles e os professores" (p. 121). Logo, devemos trilhar caminhos que possibilitem um diálogo mais compreensivo entre todos os envolvidos na escola. Segundo Assman e Sung ${ }^{6}$ temos que desenvolver laços afetivos e estes devem ser trabalhados tanto em ambientes da sala de aula quanto nos demais espaços da escola, e seu estímulo deve ser constante e vigilante.

Para DANTAS ${ }^{10}$, pautado em Wallon na criança "instrumentada pela função simbólica, a percepção de si poderá transformar-se em 'consciência de si" (p. 94). E este processo se faz pela oposição e negação do outro: "é pela expulsão do que há de alheio dentro de si, que se fabrica o Eu" (p. 94). E prossegue afirmando que:

É este drama que ocupa dominantemente o quarto, o quinto e o sexto ano, numa sucessão de manifestaçôes que vão desde a rebeldia e o negativismo em estado quase puro, à seduçáo do outro e depois à sua imitação. Conquistado na batalha, o eu ainda frágil precisa da admiração alheia para completar a sua construçáo, e assim, oferece-se em espetáculo.

A dinâmica da escuta empática era enfatizada em cada encontro e possibilitou que as crianças descobrissem a necessidade da escuta do outro, pois segundo uma criança participante do projeto: "quando uma pessoa fala é importante ouvir, porque ela fala uma coisa importante para ela e precisamos respeitar". Num relatório feito pela professora, ela mencionou que "durante a semana as crianças já estavam utilizando alguns conteúdos trabalhados; principalmente o hábito de escutar quando alguém está falando".

Uma dinâmica bastante ilustrativa utilizada no projeto para pensarmos a questão da empatia, foi a vivência da "Teia". Trata-se de uma atividade em que um aluno segura a ponta do rolo de barbante, fala seu nome e joga-o a outra pessoa, assim sucessivamente. No final, é criada uma grande teia envolvendo a participaçáo de todos. Resgatando uma passagem das anotaçóes produzidas pelo facilitador/pesquisador: "Através da canção e da inclusão de cada criança nesta teia mostramos a elas que todas estavam conectadas e quando uma criança sentisse alguma coisa as outras também podiam sentir e o que eu faço de um lado da teia meu amigo pode perceber. Sendo assim, as crianças que queriam expressar alguma coisa puxavam o barbante e todos podiam sentir o movimento da teia e assim nós sabiamos que o amigo queria falar". No relatório feito pela professora, ela menciona: "As atividades de hoje foram bastante interessantes. A que mais chamou a minha atenção foi a teia, pois para eles ficou claro que quando um coleguinha tem um problema, todos nós sentimos e por isso deve ser do nosso interesse cuidar para que todos estejam bem".

No diário de campo do pesquisador é apresentado um episódio ocorrido durante a montagem de uma peça de teatro pelas próprias crianças que faz referência a empatia: "Um fato que chamou a atençâo foi quando um menino não quis mais fazer o papel do personagem na história, pois náo conseguia decorar o texto e seu amigo de forma bem carinhosa conversou com ele, ajudando-o, soprando para ele toda a fala." $\mathrm{O}$ ato de perceber o problema do outro e estar disposto a ajudar é um dos aspectos que caracteriza uma atitude empática. Segundo Assman e Sung a empatia é um aspecto importante da afetividade e está relacionada ao desenvolvimento de competências sociais para a vida na sociedade.

Uma outra atividade proposta no quinto encontro do projeto foi a confecção do coração de tecido vermelho com enchimento de espuma. Nesta dinâmica, as crianças costuraram um coração que tinha como finalidade trazer para um plano mais lúdico o sentimento de empatia. Desse modo, quando algum aluno tinha algum problema na sala de aula, a professora pegava o coração dela e a criança o seu e eles conversavam "de coração para coração". Nesta ocasiāo, chamou à atenção a fala de um aluno que relatou que quando a avó dele ficou brava com ele, ele disse: "Vó vamos conversar de coração para coraçáo”. (Criança 5) 
Outra dinâmica que teve como objetivo o trabalho com o tema da empatia foi a visualização do talismã. Esta dinâmica tinha como objetivo identificar aquela pessoa que era sua fonte de carinho. Segundo observaçóes do diário de campo: "aquela pessoa que você mais ama é seu talismã e ele tem poder. Quando você estiver triste e com algum problema basta você fechar os olhos que você vai ficar bem e com muito amor no seu coraçâo". Após falar isso, foi perguntado para as crianças se já haviam encontrado um talismã em suas vidas, e elas responderam que sim. $\mathrm{Na}$ visualização, algumas disseram encontrar cinco, outras dez, e a cada hora que fechavam os olhos encontravam mais. De repente, uma criança disse para as demais que ela estava começando a ver que "todos são seus talismâs porque ela pode gostar de todos" (Criança 1).

A questáo do respeito mútuo e a capacidade da escuta empática também estiveram presentes nos questionários respondidos pelas próprias crianças no final do projeto, como é possível notar nos recortes copiados abaixo: Eu aprendi o quanto é importante respeitar e escutar as pessoas (Criança 2). Eu aprendi a prestar mais atenção quando alguém está explicando (Criança 3). Eu aprendi que quando um fala o outro escuta e é bem melhor (Criança 4). A escola é legal com o círculo do amor, porque começamos o dia com mais amor e respeito (Criança 5).

De acordo com o relatório produzido pela professora, no terceiro encontro, os aspectos ligados à empatia, trabalhados em cada uma das atividades do Projeto Educoração, foram sendo cultivados e mantidos na rotina semanal: "as terças-feiras mostraram-se tão cativantes aos alunos que o respeito entre eles permanecia ao longo do dia, por isto comecei a fazer o circulo do amor todos os dias".

\section{Autoestima}

A autoestima relaciona-se ao valor que as pessoas dão a si mesmas, às suas características pessoais e, segundo BEZERRA ${ }^{1}$, afeta diretamente o aprendizado do aluno por oferecer uma estrutura emocional para lidar com as adversidades. $\mathrm{O}$ projeto Educoração ao proporcionar, por meio de suas dinâmicas, a possibilidade das crianças vivenciarem e conhecerem suas emoçóes, ao mesmo tempo, permite que elas desenvolvam o respeito por si mesmas, fundamental para a construção da autoestima.

Esta questáo fica evidente na entrevista com a diretora da escola que contou sobre o caso de uma menina que tinha um problema de incontinência urinária, fato que deixava a criança constrangida atrapalhando seu desenvolvimento em aula: "Notei uma mudança muito grande nela (aluna), pois ela sempre vinha para a escola mal arrumada e às vezes nem escovava os dentes. Semana passada a vi toda arrumada e perguntei: o que aconteceu? E ela disse: você viu como o projeto tá me fazendo bem?"

A educadora também enfatizou que a melhora da autoestima das crianças participantes influenciou no aprendizado: "O que achei mais interessante no projeto são as músicas que trazem uma mensagem diferente para cada vivência desenvolvida ajudando no clima de alegria, melhora da autoestima e amor que se estabelece. As crianças se sentem mais confiantes $e$ amadas e isto interfere no aprendizado, pois ele fica mais interessado".

Ressaltamos também que após a análise do material obtido nos oito encontros, pudemos perceber que as crianças demonstraram uma maior abertura para manifestarem-se, deixando a inibiçáo para expressar aspectos subjetivos de si que, às vezes, não encontram espaço para serem compartilhados na escola, o que pode revelar uma maior confiança em si mesmas e afetar diretamente a convivência na sala de aula.

Nos primeiros encontros, grande parte das crianças se apresentou de maneira muito tímida, mal se ouviam suas vozes e muitas delas somente repetiam o que as outras haviam dito. Se alguma pergunta era feita, as respostas tendiam a ser a mesma, porém com o desenrolar do projeto ocorreu uma mudança nestes espaços de conversa, a inibição foi dando lugar a escuta de suas emoções (ludicamente representada pelo coração que eles construíram) e foi sendo criada uma relação mais afetiva que possibilitou à professora conhecer seus alunos, suas dificuldades e criar maneiras de intervir no ensinamento. Segundo a professora: "As rodas de conversas tornaram-se rotinas do dia, pois possibilitaram que eu ajudasse a construir maneiras diferentes para ajudar os alunos, fortalecendo a confiança quanto o aprendizado de cada um".

\section{Aprendizagem}

Várias pesquisas falam da ligação direta existente entre afetividade, cognição e aprendizagem ${ }^{20}$. Para WALLON ${ }^{9}$, a relação entre afetividade e inteligência é de alternância, podendo as primeiras emoçôes criar estruturaçóes cognitivas. Por isso a importância de trabalhar com a afetividade para a construçáo de uma aprendizagem mais ampla e efetiva. 
Mahoney e Almeida ${ }^{12}$ afirmam que quando não são satisfeitas as necessidades afetivas, estas resultam em barreiras para o processo ensino-aprendizagem e, portanto, para o desenvolvimento, tanto do aluno como do professor. Indo ao encontro destas afirmações, durante o desenvolvimento do projeto pudemos perceber esta interação entre a afetividade e a aprendizagem por parte dos alunos. Hazin, Frade e FalCÃo ${ }^{21}$ realizaram estudo relacionando a afetividade, na dimensão da autoestima, com desempenho escolar em matemática e, embora os dados não permitam reconhecer uma relação causal em uma determinada direção, foi possível verificar uma conexão empírica entre os aspectos envolvidos.

Segundo relato da professora foram várias as mudanças ocasionadas pelas atividades do projeto no processo de ensino-aprendizagem da turma, compreendendo melhoras na atenção, na participaçáo e na concentração dos alunos. A mudança da disposição da sala de aula influenciou também no processo de ensino: "Logo nos encontros iniciais foram retiradas as carteiras e cadeiras, a mudança da disposição na sala de aula conferiu maior liberdade de expressão para as crianças e melhora na atenção deles".

Uma estratégia que auxiliou no processo da aprendizagem como um todo segundo a descrição do facilitador foi a prática das posturas de yoga, utilizadas em cada encontro. Estes exercícios eram ensinados ao longo de cada história, como aqueles apresentados no "Monstro que roubou o vermelho"c. Baseados nos personagens e fatos ocorridos ao longo da história foi ensinada a postura da montanha - com a finalidade de trabalhar com o equilíbrio físico e emocional; a postura do leão que ajuda na melhoria da expressão e timidez; e a postura do bebê - indicada para a impaciência. Durante a execuçáo destes exercícios foram feitos alguns relatos interessantes por parte das crianças:"Me sinto mais alta e em paz como borboleta" (Criança 8, relatório facilitador/pesquisador).

Foi percebido pelos facilitadores que paulatinamente a atenção das crianças melhorava e durante as posturas se dispersavam menos, buscando sentir mais os efeitos de cada exercício no seu próprio corpo. Algumas crianças começaram a perceber que quando falam não conseguem se equilibrar. Aos poucos elas próprias começaram a trazer elementos para a criaçáo de mais posturas. "Uma delas trouxe a ideia de que no alto da montanha tinha também um macaco, e nós imitamos o macaco, e foi bem engraçado e descontraido." (relatório facilitador/pesquisador) provando que é importante o professor estar atento àquilo que as crianças trazem para a contribuição do processo de aprendizagem ${ }^{3}$, ou para o que ArAújO ${ }^{22}$ chama de papel ativo dos alunos.

Consoante a FreIre ${ }^{3}$, o aprendizado é construído a partir da bagagem adquirida do aluno em conjunto com aquela relativa ao conhecimento do professor, desse modo, a aprendizagem concretizase pela ação de ambos e cabe ao professor estar atento para reconhecer os conteúdos trazidos pelos alunos e recorrer às suas experiências para a construçáo do aprendizado.

Além destes momentos proporcionados pelas posturas de yoga, as cançóes e a contação de histórias do projeto eram de grande encantamento para as crianças. "De forma bastante interativa, a cada semana as crianças participavam mais das discussóes, realizavam as posturas ensinadas durante os encontros bem como decoravam algumas cançôes relativas ao tema tratado no dia" (relatório educadora).

Na história do "Monstro que roubou o vermelho", há um momento em que surge a mulher sábia, ensinando sobre como proceder em momentos incertos e de muito medo. O grande desafio desta história era encontrar o monstro e convencê-lo a devolver a cor vermelha para o mundo. Ao responderem sobre o que mais gostaram na história, as crianças escreveram: Do leão bravo que quando mandamos amor ele virou um gatinho bonitinho! (Criança 3). Da mulher sábia que dá o coração mágico e ensina que é só mandar amor quando se tem medo. (Criança 5).

$\mathrm{Na}$ entrevista final, após os encontros presenciais com as crianças, a educadora novamente ressaltou aspectos relativos à empatia e a melhora na relação professor-aluno. Respondendo à pergunta: "Você percebeu alguma mudança na sala de aula após o projeto?", a educadora disse: "Bom, no inicio tive um certo receio deste projeto atrapalhar o cumprimento do curriculo, no entanto, com o passar dos dias o projeto contribuiu muito, ao passo que mudei a maneira de intervir em alguns comportamentos que prejudicava $o$ andamento da sala de aula, e hoje vejo que não perdi tempo com a proposta, mas ganhei em rendimento da sala a medida que as crianças escutam e realizam as tarefas com mais entusiasmo".

$\mathrm{Na}$ mesma entrevista, a educadora mencionou ainda melhoras com relaçáo ao relacionamento interpessoal entre os próprios alunos: "Observei que as crianças apresentaram maior afetividade em relação aos colegas e passaram a se expressar mais e melhorou o aproveitamento das aulas em relaçáo aos conteúdos, pois agora parecem ver significado no que aprendem." 


\section{Discussão}

As atividades do Educoração contribuíram de maneira direta para que fossem abordados diversos aspectos relativos à afetividade e ao convívio das crianças na escola. As experiências do projeto geraram frutos: além da mudança nas relaçóes entre as crianças e a professora e, da maior atenção de uns com os outros, a professora relatou que depois das intervenções conseguiu realizar seu trabalho com maior engajamento e interesse dos alunos, fato que permitiu que o projeto se ramificasse para outras turmas na escola.

Outro fator importante no impacto deste projeto no ambiente escolar, diz respeito à participação do professor no processo de mudança e no trabalho cotidiano com os alunos: as questóes levantadas pelas experiências do projeto só puderam vingar, pois começaram a fazer parte do dia-a-dia escolar. Com isso em um pequeno espaço de tempo pôdese obter um quadro de mudanças significativas no comportamento dos alunos. Sem estes pilares de atuação conjunta talvez o tempo de análise fosse insuficiente para se obter tais resultados.

Entendemos que um trabalho que se coloque a discutir questóes ligadas a este tema deve trazer consigo propostas para que um novo possa de fato se concretizar em torno de uma educação afetiva, de um ensino que preze pelo respeito e por laços afetivos entre os envolvidos ${ }^{23}$.

As atividades do projeto trabalhavam com diversos potenciais e estava implícita, em cada gesto, a importância da via afetiva no processo de mudança que foi instaurando-se. Ao confeccionar os coraçóes, as crianças foram estimuladas náo só em sua coordenação motora, mas também em elementos de amorosidade e paciência. As habilidades artísticas observadas no desenho do "Monstro que roubou o vermelho" também espelharam medos e, ao final da história, a capacidade de transmutá-los. A agitação observada na classe aos poucos foi sendo trabalhada com os exercícios de relaxamento e meditação.

Ao tratar das histórias por meio dos conjuntos funcionais propostos por MaHoney e Almeida ${ }^{12}$ pautados em Wallon ${ }^{7}$ : afetivos, dos sentimentos; de ato motor, com as encenaçóes, poses de yoga e vivências; e cognitivo, com as reflexóes sobre as atividades, as propostas trabalhadas propiciaram a integração no conjunto funcional da pessoa, que integra todos os outros mencionados.

Certamente, o projeto Educoração deixou muitas histórias na cidade de Cerquilho. As experiências vivenciadas na escola durante os meses do projeto repercutiram de maneira positiva tanto para os propositores do projeto, quanto para a escola e para as crianças. Os momentos de empatia e de amorosidade estão registrados não só aqui, mas no coração de cada uma delas, no cultivo da empatia, na firmeza perante os obstáculos, no exercício de ouvir e se colocar no lugar do outro.

A afetividade não pode ser conseguida apenas por meio dos livros, ela deve ser cultivada a cada dia, no cuidado com o aluno, na atenção aos seus problemas, na proposição de soluções e nas ações de grupo.

Conforme demonstrado neste tempo de pesquisa, as posturas de yoga, as histórias, as cançóes e as rodas de conversa são estratégias que auxiliam neste processo e que podem ser utilizadas sistematicamente em sala de aula. Porém, para todas elas, é necessário que haja um sentimento muito forte por parte do educador de acreditar naquilo que faz e cultivar a empatia nas relaçóes com os alunos.

Esta é uma das inúmeras histórias que podem ser contadas em favor de um cenário escolar a favor $\mathrm{da}$ afetividade, que leve em conta as diferenças e as trabalhe com maior empatia.

\section{Notas}

a. Localizado no município de Porangaba, interior de São Paulo, o Instituto Visão Futuro foi criado para facilitar e co-criar uma visão de mundo mais cooperativa e humanizada, desenvolvendo projetos e atuando em diversos setores sociais.

b. O Espaço CreSer recebe crianças do entorno e filhos dos 40 funcionários que trabalham no Instituto.

c. A história do "Monstro que roubou o vermelho" compóe a lista de atividades do projeto Educoração e pode ser encontrada no manual do Educoração (Andrews, 2007). 


\section{Abstract}

\section{Educoração: stories, experiences and learning of shares and affectivity at school}

The present study aims to analyze the proposed Educoração, a project created to act in the child's emotional development that uses various tools (songs, rounds of conversation, cooperative games, yoga poses and storytelling) to be held in the scholar context. The implementation was done in a public school of Cerquilho city (SP) in 8 meetings of a duration of one hour and a half, once a week, with 23 children in the first year of elementary school. This is a participatory research and as a methodological process were used observations, reports, interviews semi-structured with the group's teacher and principal and questionnaires. The data were discussed through three broad categories of analysis: empathy, self-esteem and learning. The results showed that, added to the teacher's participation in change process and daily work with their students, the techniques of Educoração have positively influenced the affection of children and promoted an improvement in the daily life of the classroom. The activities of Educoração contributed in a direct way for them to be addressed many aspects of affectivity and coexistence of children in school. Besides the change in relations between the children and the teacher, and the greatest attention to each other, the teacher reported that after interventions could carry out their work with greater commitment and interest of students, a fact that allowed the project to ramify other classes in the school.

KEYWORDS: Affectivity; Education; Learning; Elementary school.

\section{Referências}

1. Bezerra RJL. Afetividade como condição para a aprendizagem: Henry Wallon e o desenvolvimento cognitivo da criança a partir da emoção. REDSIS. 2006;4: 20-6.

2. Almeida ARS. A afetividade no desenvolvimento da criança: contribuições de Henri Wallon. Inter-Ação. 2008;33:343-57.

3. Freire P. Pedagogia da autonomia: saberes necessários à prática educativa. 33a ed. São Paulo: Paz e Terra; 2005.

4. Garcia J. O que desejam os indisciplinados? Anais do 9o Congresso Nacional de Educação e 3o Encontro Sul Brasileiro de Psicopedagogia; 2009 out. 26-29; Curitiba: Champagnat; 2009. p. 7127-36.

5. De Oliveira J, Gomes M. Bullying: reflexôes sobre a violência no contexto escolar. Educação Por Escrito. 2012;2:1-14.

6. Assman H, Sung JM. Competência e sensibilidade solidária: educar para a esperança. 2a ed. Petrópolis: Vozes; 2000.

7. Wallon H. As origens do pensamento na criança. São Paulo: Manole; 1989.

8. Leite SAS, Tagliaferro AR. A afetividade na sala da aula: um professor inesquecível. Psicol Esc Educ. 2005;9:247-60.

9. Wallon H. A evolução psicológica da criança. São Paulo: Martins Fontes; 2007.

10. Dantas H. A afetividade e a construção do sujeito na psicogenética de Wallon. In: Taille Y, Oliveira MK, Dantas H, organizadores. Piaget Vygotsky Wallon: teorias psicogenéticas em discussão. São Paulo: Summus; 1992.

11. Ferreira AL, Acioly-Régnier NM. Contribuições de Henri Wallon à relação cognição e afetividade na educação. Educar. 2010;36:21-38.

12. Mahoney AA, Almeida LR. Afetividade e processo ensino-aprendizado: contribuiçôes de Henri Wallon. Psicol Educ. 2005;20:11-30.

13. Cavallet VJ. Educação formal e treinamento: confundir para doutrinar e dominar. Diálogo Educ. 2000;1(2):1-170.

14. Galvão L. Expressividade e emoçôes segundo a perspectiva de Wallon. In: Arantes VA, organizador. Afetividade na escola: alternativas teóricas e práticas. São Paulo: Summus; 2003. p. 71-88.

15. Alves R. A Alegria de ensinar. São Paulo: Ars Poética; 1994.

16. Andrews S. O círculo de amor: para abrir o coração. São Paulo: Graphpress; 2007.

17. Minayo MCS. Trabalho de campo: contexto de observação, interação e descoberta. In: Minayo MCS, organizadora. Pesquisa social: teoria, método e criatividade. Rio de Janeiro: Vozes; 2007. p. 61-78.

18. Bardin L. Análise de conteúdo. Trad. Luis Antero Reto e Augusto Pinheiro. Lisboa: Edições 70; 2004.

19. Hess R., Weigand G. La relation pédagogique. Paris: Armand Colin; 2004.

20. Saltini C. Afetividade e inteligência. Rio de Janeiro: DPA; 1997.

Rev Bras Educ Fís Esporte, (São Paulo) 2018 Abr-Jun;32(2):233-42・241 
Batista JC, et al.

21. Hazin I, Frade C, Falcão JTR. Auto estima e desempenho escolar em matemática: contribuiçốes teóricas sobre a problematização das relaçôes entre cognição e afetividade. Educar. 2010;36:39-54.

22. Araújo UF. A dimensão afetiva da psique humana e a educação em valores. In: Arantes VA, organizador. Afetividade na escola: alternativas teóricas e práticas. São Paulo: Summus; 2003. p. 153-169.

23. Maturana H, Verden-Zöller G. Amar e brincar: fundamentos esquecidos do humano. São Paulo: Palas Athena; 2004.

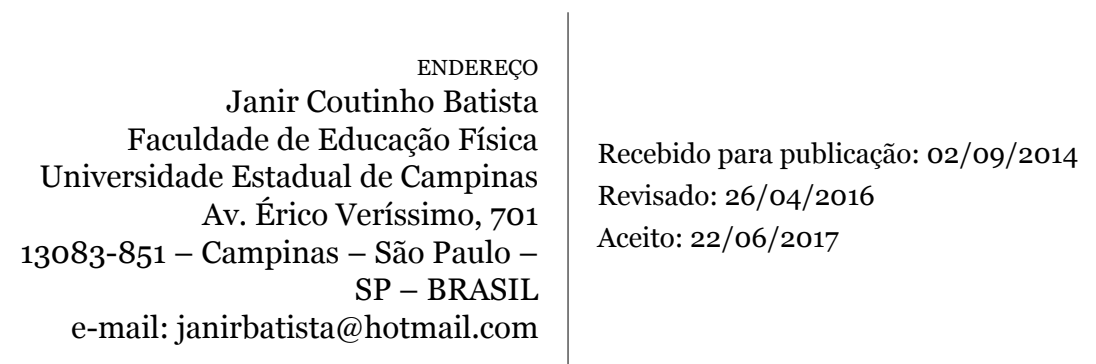

